\title{
Five Graduate Students to Receive Awards at MRS Spring Meeting
}

At its 1989 Spring Meeting in San Diego the Materials Research Society will recognize five outstanding graduate students whose work has been judged to be exceptional. The students will be recognized during the Plenary Session, Wednesday evening, April 26, 1989, which features $\mathrm{Li}$ nus Pauling. The award consists of a cash honorarium, payment of the Spring Meeting registration fee, and a certificate of achievement.

"These students were selected," said Awards Committee Chair John Baglin, "for outstanding performance in the conduct of research which closely relates to a Spring Meeting symposium topic, the originality of the contribution, significant and timely research results, and the promise for substantial future achievement in materials research."

The 1989 MRS Spring Meeting graduate award recipients and papers being presented are:

Symposium C-Hing Wong, University of California, Berkeley, "Impurity Gettering with Plasma Immersion Implantation" (Tuesday, April 25, 2:45 p.m.), and "The
Gettering Mechanism of Implanted Carbon in Silicon" (Tuesday, April 25, 3:30 p.m.)

Symposium D-Chia-Hong Jan, University of Wisconsin, Madison, "The Growth Rates of Intermediate Phases from Diffusion Couples: Bulk Versus Thin-Film Studies" (Monday, April 24, 11:00 a.m.)

Symposium E-Gregory N. Parsons, North Carolina State University, "Substrate Interactions in the Formation of Amorphous Silicon/Dielectric Interfaces for FET Device Structures" (Wednesday, April 26, 12:20 p.m.)

Symposium J-Lai-Kwan Chau, Iowa State University, "Fluorinated Monomolecular Assemblies: Model Systems to Probe Chemical Interactions at the Polymer-Metal Interface" (Wednesday, April 26, 2:45 p.m.)

Symposium J-Neil A. Coombs, University of Toronto, "Mechanical and Chemical Characterization of a Metal-Bioceramic Interface" (Tuesday, April 25, 7-10 p.m., poster paper J4.1)

\section{North Texas Section to Hold Joint Meeting}

The North Texas Materials Characterization Society is again making plans for a joint meeting with the Texas Chapter of the American Vacuum Society and the North Texas Section of the Electrochemical Society. The eighth in a series of annual joint meetings, this year's meeting also encompasses the Fourth Annual Symposium of the Texas Chapter of AVS.

Scheduled June 5-6 at the Richardson Hilton, Richardson, Texas, this year's joint meeting will concentrate on electronic materials, processing, and characterization.

Student paper presentations will be judged and prizes awarded for first $(\$ 150)$ and second $(\$ 100)$ place.

For further information, contact:

Marylyn Bennett-Lilley (214) 995-0821,

Allen Bowling (214) 995-3195, or

Roc Blumenthal (214) 995-2329.

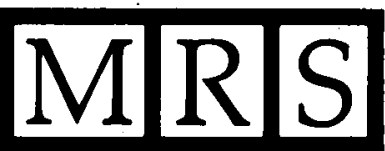

\section{William H. Price Scholarship in Optical Engineering}

Applications are being accepted for the William H. Price Scholarship in Optical Engineering. The scholarship, independently established in 1985, will be awarded to a student in the field of optical design and engineering.

This year's award of $\$ 4,000$ will be announced in June 1989.

\section{Selection criteria:}

- Candidates must be full-time graduate or undergraduate students of optical design and engineering.

- Candidates must submit an original report (3-5 pages maximum) summarizing their research or technical work specifically in optical design and engineering.

The report, along with an application form, must be postmarked by May 15, 1989 and mailed to the address below. Up to two letters of recommendation may be sent under separate cover to the same address.

For information and application forms, contact:

The William H. Price Scholarship in Optical Engineering

c/o Jan Huston, SPIE

P.O. Box 10, Bellingham, WA 98227-0010

telephone (206) 676-3290

$\operatorname{tax}(206) 647-1445$ 


\section{NEW}

MODEL LTS-22-MAC CLOSED CYCLE Materials Analysis Cryostat

This versatile, new system has been designed to satisfy new requirements generated by the recent discovery of the exciting new group of "High Temperature Superconducting Materials."

- For Hall Effect, resistivity, Meissner measurements, etc.

from $<15$ to $350 \mathrm{~K}$

GREATER ACCURACY

- Separate temperature sensors for control and sample readouts.

- Analog heater output from Series 4000 Temperature Controller gives superior control at low temperatures.

- Exchange gas sample environment virtually eliminates sample temperature gradients. GREATER SPEED

- Easy-to-operate sample space airlock valve.

- Quick select 3-way valve for sample space, vacuum or exchange gas.

- No need to shut down refrigerator or break main vacuum during sample change.

- Larger, 3/4" diameter sample space permits multiple samples GREATER RELIABILITY

- Proven Gifford-McMahon refrigerator technology.

- Lower self-induced vibration.

10,000 hour service interval.

- Rigorous quality control.

- Matching Meissner coil system PLUS

- Custom sample probes. - Water or aircooled compresso

QUICK DELIVERY

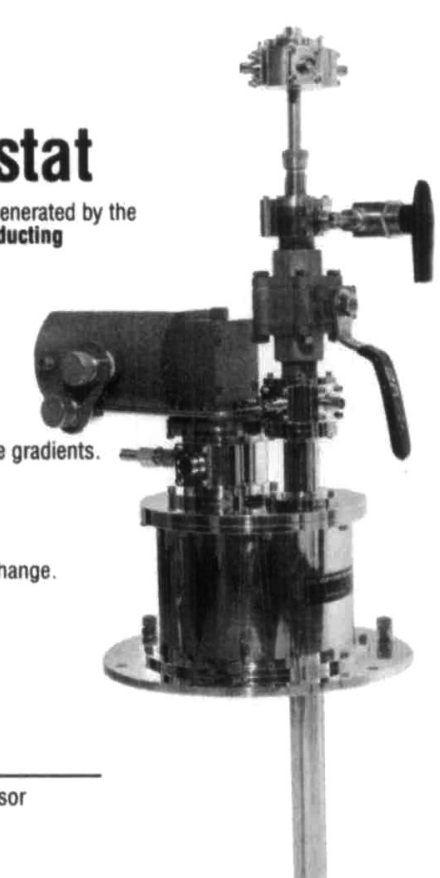

RMC CRYOSYSTEMS ,

DUR 21ST YEAR SEAVINGTHE

1802 W. Grant Rd., Suite 122, Tucson, AZ 85745

(602) 882-7900 Telex 24-1334 Fax (602) 628-8702

\section{In the Next Issue:}

Guest Editor Yen T. Tan of Eastman Kodak's Photographic Research Laboratories focuses on "Silver Halides in Photography" in a special introductory article and four feature articles:

"The Unique Electronic Properties of the Silver Halides" by Frederick C. Brown, University of Washington

"Defects in Silver Halides" by C.R.A. Catlow, University of Keele

"Studies of lon Transport in $\mathrm{AgCl}$ and $\mathrm{AgBr}$ " by P.W.M. Jacobs, University of Western Ontario

"The Improbability of the Photographic Process, or what Makes the Silver Halides Unique?" by Lawrence Slifkin, University of North Carolina
HIGH PURITY METALS CATALOG FROM A ${ }^{\text {ro }}$...

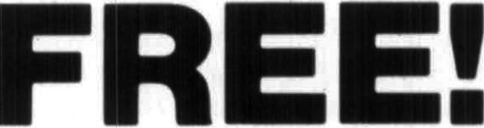

At ESPI we have every metal you need-in stock \& available for immediate delivery:

\begin{tabular}{|c|c|}
\hline ALUMINUM & MERCURY \\
\hline ANTIMONY & MOLYBDENUM \\
\hline ARSENIC & NEODYMIUM \\
\hline BARIUM & NICKEL \\
\hline BERYLLIUM & NIOBIUM \\
\hline BISMUTH & OSMIUM \\
\hline BORON & PALLADIUM \\
\hline CADMIUM & PHOSPHORUS \\
\hline CALCIUM & PLATINUM \\
\hline CERIUM & POTASSIUM \\
\hline CESIUM & PRASEODYMIUN \\
\hline CHROMIUM & QUARTZ \\
\hline COBALT & RHENIUM \\
\hline COPPER & RHODIUM \\
\hline DYSPROSIUM & RUBIDIUM \\
\hline ERBIUM & SAMARIUM \\
\hline EUROPIUM & SAPPHIRE \\
\hline GADOLINIUM & SCANDIUM \\
\hline GALLIUM & SELENIUM \\
\hline GERMANIUM & SILICON \\
\hline GOLD & SILVER \\
\hline GRAPHITE & SODIUM \\
\hline HAFNIUM & TANTALUM \\
\hline HOLMIUM & TELLURIUM \\
\hline INDIUM & TERBIUM \\
\hline IODINE & THALLIUM \\
\hline IRIDIUM & TIN \\
\hline IRON & TITANIUM \\
\hline LANTHANUM & TUNGSTEN \\
\hline LEAD & VANADIUM \\
\hline LITHIUM & YTTERBIUM \\
\hline LUTETIUM & YTTRIUM \\
\hline MAGNESIUM & ZINC \\
\hline MANGANESE & ZIRCONIUM \\
\hline
\end{tabular}

And you'll find them in: Rod, Wire, Sheet, Shot, Foil, Bar, Pellets, Powder, Evap Sources, Sputtering Targets, Compounds-in high purity form from 99.9 to 99.9999 and they're easily found in our "Free" catalog.

Call us or write today!

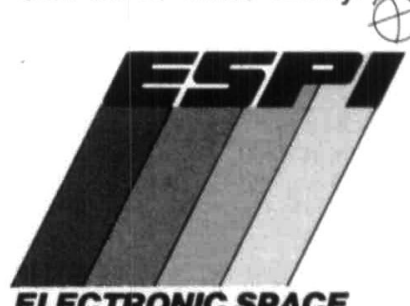
PRODUCTS INTERNATIONAL

5310 Derry Avenue

Agoura Hills, CA 91301

CA: 800 848-7873 ILX: 3715810

US: 800 638-2581 FAX: 818-889-7098 LOCAL: 818-991-6724 